\title{
Looking back, moving forward: Implementing PMTCT programs in resource-constrained settings, Horizons studies 1999 to 2007
}

Carolyn Baek

Naomi Rutenberg

Population Council

Follow this and additional works at: https://knowledgecommons.popcouncil.org/departments_sbsr-hiv

Part of the Demography, Population, and Ecology Commons, Family, Life Course, and Society

Commons, International Public Health Commons, and the Medicine and Health Commons

How does access to this work benefit you? Let us know!

\section{Recommended Citation}

Baek, Carolyn and Naomi Rutenberg. 2010. "Looking back, moving forward: Implementing PMTCT programs in resource-constrained settings, Horizons studies 1999 to 2007," Horizons Synthesis Background Papers. Washington, DC: Population Council. Version of record: https://doi.org/10.1177/ 003335491012500220 


\section{LOOKING BACK, MOVING FORWARd}

\section{Implementing PMTCT Programs in}

Resource-Constrained Settings

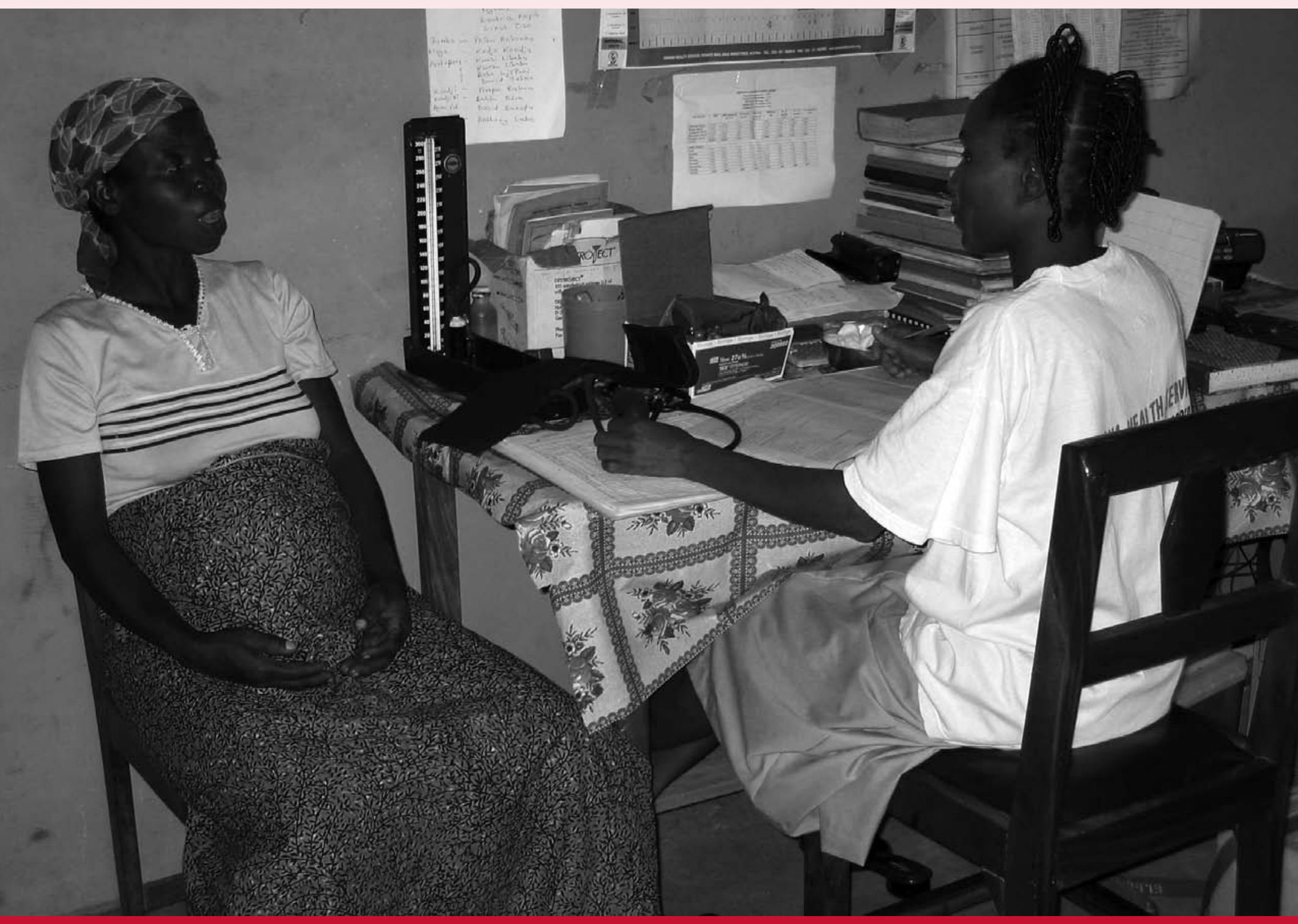

\section{HORIZONS StUdIES 1999 to 2007}




\section{Hgrizons}

In 1997, the Population Council initiated the Horizons Program—a decade-long USAID-funded collaboration with the Family Health International, the International HIV/AIDS Alliance, Johns Hopkins University, International Center for Research on Women, PATH, Tulane University, and the University of Alabama at Birmingham - designing, implementing, evaluating, and expanding innovative strategies for HIV prevention and care.

Horizons developed and tested ways to optimize HIV prevention, care, and treatment programs; worked to reduce stigma and improve gender-biased behaviors; and greatly expanded knowledge about the best ways to support, protect, and treat children affected by HIV and AIDS. In all its projects, Horizons strengthened the capacity of local institutions by providing support and training to colleagues.

This series of synthesis papers presents lessons learned and best practices on six key topics that Horizons investigated: HIV-related stigma, access to antiretroviral therapy, men who have sex with men, orphans and vulnerable children, HIV and gender, and prevention of mother-to-child transmission of HIV. 


\section{Implementing PMTCt Programs in Resource-Constrained Settings}

Each year more than 430,000 infants are infected with HIV, most in sub-Saharan Africa and most due to mother-to-child, or "vertical", transmission. In the late 1990s, breakthrough clinical trials of shorter and less expensive antiretroviral regimens demonstrated reductions of about 50 percent in vertical transmission. These advances made the prevention of mother-to-child transmission (PMTCT) of HIV affordable in sub-Saharan Africa and other resource-constrained settings. During the early stages of program implementation, the Population Council's Horizons Program conducted operations research in several sub-Saharan African countries to determine how interventions that were successful in the clinical trial setting would translate to actual health care delivery in low-resource settings. The first set of studies documented the feasibility and challenges of PMTCT programs, while the second assessed quality of services and effectiveness of strategies to promote utilization and adherence to recommended practices.

\section{Introduction}

Each year more than 430,000 infants are infected with HIV [1], most in sub-Saharan Africa and most due to mother-to-child, or "vertical", transmission. In marked contrast, mother-to-child transmission of HIV has been virtually eliminated in high-resource settings through the use of several strategies. In these settings, nearly all HIV-positive mothers use antiretroviral therapy (ART) during pregnancy, labor, and for the infant postpartum. They deliver their babies via cesarean section to reduce the infant's exposure to trauma and infection in the birth canal. And new mothers use an exclusive method of infant feeding [2]. (Exclusively using one feeding method, in comparison to mixing breastfeeding and formula feeding, re- sults in reduced risk of HIV transmission [12].) While effective, these interventions are costly and require strong health care systems to deliver them.

In the late 1990s, breakthrough clinical trials of shorter and less expensive prophylactic antiretroviral regimens - a short course of zidovudine for the mother or a single dose of nevirapine to mother and infant-demonstrated reductions of about 50 percent in vertical transmission [3, 4]. These advances made the PMTCT of HIV affordable in sub-Saharan Africa and other resource-constrained settings.

Based on these clinical trial results, PMTCT pilot programs were designed and implemented in 11 developing countries under the leader- 
ship of UNICEF. These pilot programs, introduced in 1999, included voluntary counseling and testing (VCT) for HIV, provision of a short course of prophylactic antiretroviral medication for HIV-positive pregnant women to prevent the transmission of the virus to their newborns, and infant feeding counseling. The new HIV services were incorporated into existing infrastructure such as antenatal care, obstetrical care, family planning and maternal and child health clinics.

During this early stage of program implementation (1999-2003), the Population Council's Horizons Program conducted operations research in several sub-Saharan African countries to determine how interventions that were successful in the clinical trial setting would translate to actual health care delivery in low resource settings.

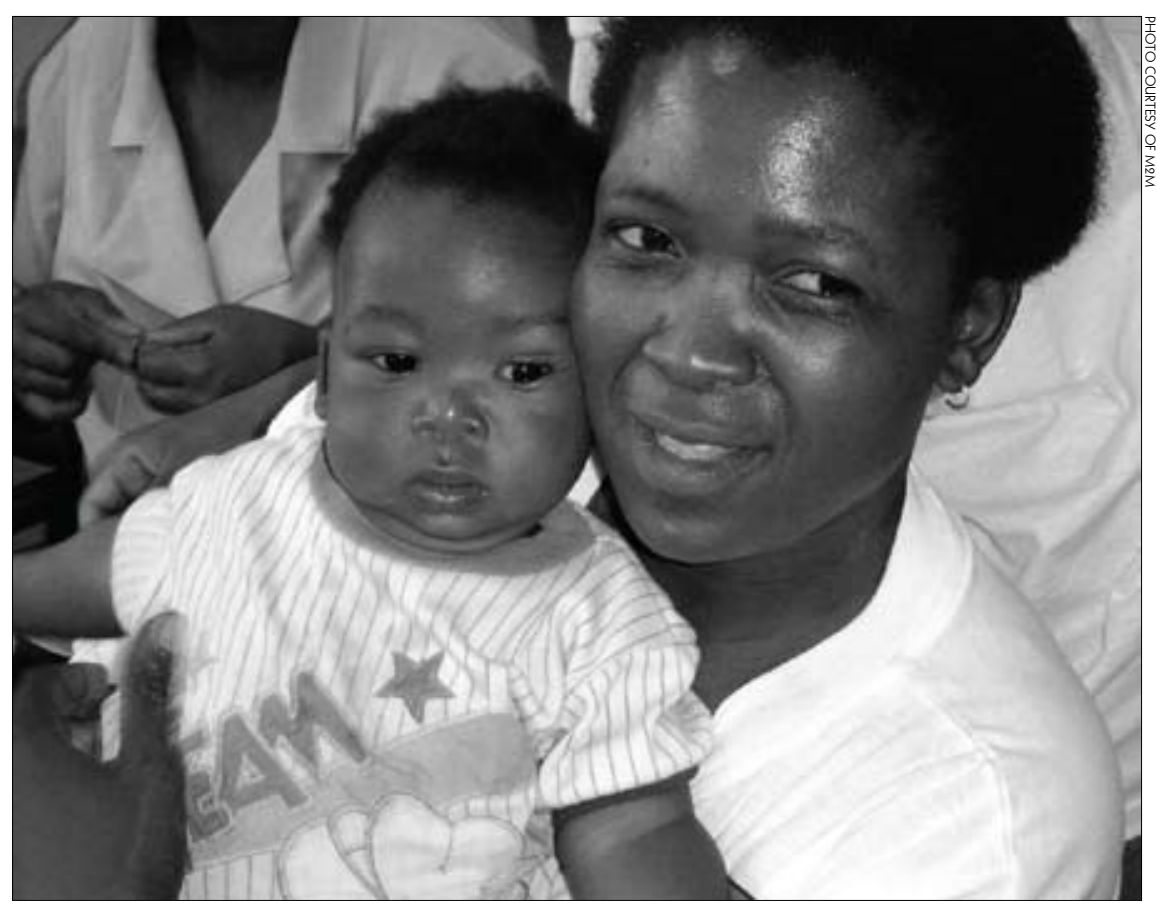

Each year more than 430,000 infants are infected with HIV, most in subSaharan Africa and most due to mother-to-child, or "vertical", transmission. The woman in this photo and her infant participated in the successful mothers 2 mothers program in South Africa, which was evaluated by the Horizons Program.
We did not know, for instance, whether it was feasible or acceptable to test pregnant women for HIV given the stigma and fear associated with a positive diagnosis, and because general antiretroviral treatment was not then available in these settings. Also unknown was whether HIV-positive pregnant women would routinely return to the clinic for refills of medication and adhere to the twice daily regimen. Further complicating matters was how best to introduce a formula feeding option. These HIV-infected mothers may not have had access to clean water and bottles and formula feeding might signal an HIV-positive status, resulting in stigma.

By the early 2000s, pilot programs aimed at preventing mother-to-child transmission of HIV were in place in numerous countries as the global health community, NGOs, governments, and international donors mobilized to fund and implement services. Programs gathered statistics about whether women used the services. However, there were little available data on the quality of programs or the effectiveness of strategies to encourage women to use services and adhere to PMTCT recommendations. A second set of Horizons studies (2004-2007) sought to gather information on these issues, as well as about the role of family planning in PMTCT programs, the value of psychosocial support for HIV-positive mothers, and ways to improve the quality of care and follow up for women in the postpartum period.

\section{Study Designs and Methods}

Horizons used a variety of approaches to studying PMTCT (Appendix). The first set of studies included studies of women and infant pairs in Kenya and Zambia to determine the feasibility, acceptability, and effect of implementing PMTCT programs outside of a controlled 
clinical setting. The second set included diagnostic and intervention studies and program evaluations. Cross-sectional surveys were used to interview pregnant or postpartum women. Studies assessing existing services (in Botswana and India) and new service-delivery models (in Kenya, South Africa, Swaziland, and Zambia) included interviews with clients, health providers, and managers; observations of client-provider interactions; and a review of records.

Most data collection activities took place at health facilities. Some studies, such as an assessment in Botswana of mothers' ability to properly administer antiretroviral prophylaxis medicines to their infants, also included home visits. The methodologies were selected to be inclusive of women targeted by the PMTCT program in the geographic area where the studies were carried out.

Careful considerations were given to minimize participant risk, such as inadvertently revealing women's HIV status through their participation in the study, and to maximize confidentiality. All studies were approved by internal review boards (IRBs) in-country as well as by the Population Council's IRB in the United States.

\section{Results}

\section{If you build it, will they come?}

Horizons' evaluation of UN-supported pilot programs and studies of women in Kenya and Zambia [5-7] found that it was feasible and acceptable to implement services to prevent mother-to-child transmission of HIV into antenatal care clinics. This included providing information on ART and antiretroviral prophylaxis, counseling and testing, and alternative infant feeding methods. There was no evidence that the introduction of HIV services into antenatal care discouraged women from accessing antenatal care.

From the beginning, though, only a fraction of women getting antenatal care received PMTCT services. The Zambia study revealed a cascade of diminishing service use from antenatal care visit (Figure 1), to HIV counseling and testing, to returning for a positive result, and receiving and ingesting antiretroviral prophylaxis. This culminated in low uptake of ART. Reasons for the low uptake included women not wanting to know their HIV status, concern about stigma, and lack of male and community support. Additionally, limited human resource capacity and insufficient supplies posed challenges to service delivery. As a consequence, the Kenyan and Zambia studies documented PMTCT coverage of 15 percent or less among HIVpositive pregnant women [6].

For those women who followed PMTCT recommendations fully, however, the programs had the hoped for outcomes. For example, among those receiving antiretroviral prophylaxis at the Lusaka, Zambia, study site, mother-to-child trans- 
mission of HIV during labor and delivery was reduced by more than 50 percent, matching clinical effectiveness [6].

These early studies also identified challenges related to infant feeding. At the time, guidelines directed providers to review the pros and cons of each recommended feeding option (e.g., breastfeeding with early weaning, exclusive formula feeding) with women [8]. The Zambia study, however, revealed that in more than one-third of counseling sessions, providers did not follow these guidelines. Instead, frequently they imposed their opinion that HIV-positive women should not breastfeed. At the same time, providers only asked in less than one-fifth of the sessions if the woman had told her partner or another family member that she was HIV-positive, even though disclosure is known to increase the chances that someone will follow treatment and prophylaxis guidelines properly. Nor did they routinely ask whether adequate water and fuel were available for the safe use of infant formula. Inadequate counseling and support regarding infant feeding was also seen in the Kenya study where most women, regardless of HIV status, were combining breast- and bottle-feeding $[6,7]$.

\section{Improving utilization and impact of PMTCT}

By the early 2000s, PMTCT pilot programs were in place but only a small proportion of HIV-positive pregnant women were being reached with services [5]. Implementation of PMTCT services at their most basic included HIV counseling and testing in antenatal care, provision of ART to HIV-positive women and their exposed infants, and infant feeding information. Another limitation of PMTCT programs introduced in the early 2000s was that most ended soon after delivery. The second phase of Horizons studies aimed to identify strategies to strengthen and expand programs, address barriers to service delivery and uptake.

\section{Psychosocial support from peers helps women adhere to PMTCT program recommendations}

The Horizons Program completed the first evaluation of mothers 2 mothers $(\mathrm{m} 2 \mathrm{~m})$, a clinic-based, peer-support program that provides education and psychosocial support to HIVpositive pregnant women and new mothers. It helps women access existing PMTCT services and follows up with mothers and infants after delivery (Figure 2). The evaluation documented that women participating in $\mathrm{m} 2 \mathrm{~m}$ were significantly more likely to:

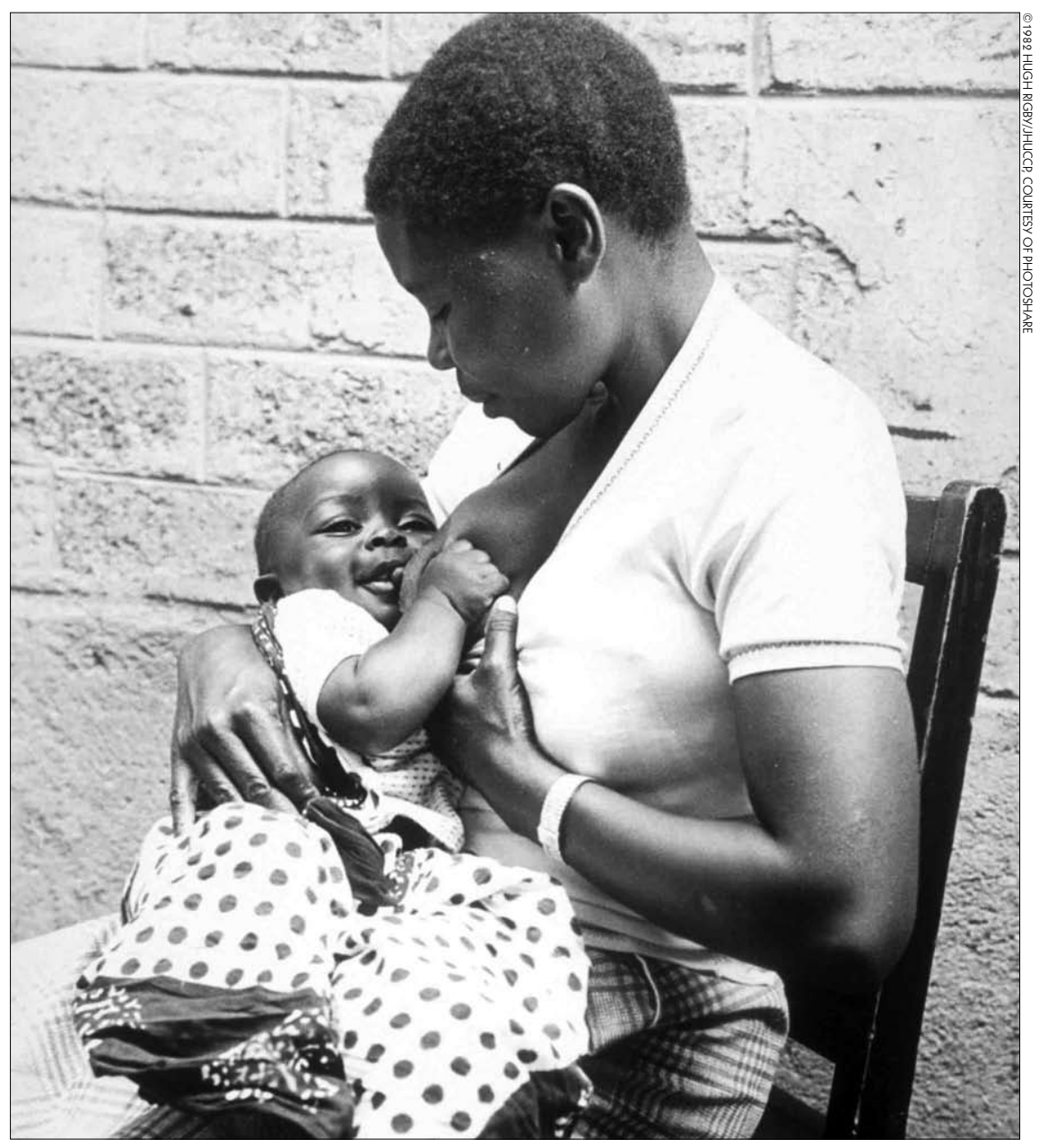

There is evidence that mixing breastfeeding and formula feeding increases the risk of HIV transmission. Exclusively using one feeding methodincluding breastfeeding — results in reduced risk of HIV transmission. 
Figure 2 Participation rates in the mothers 2 mothers program among HIV-positive postpartum women in South Africa

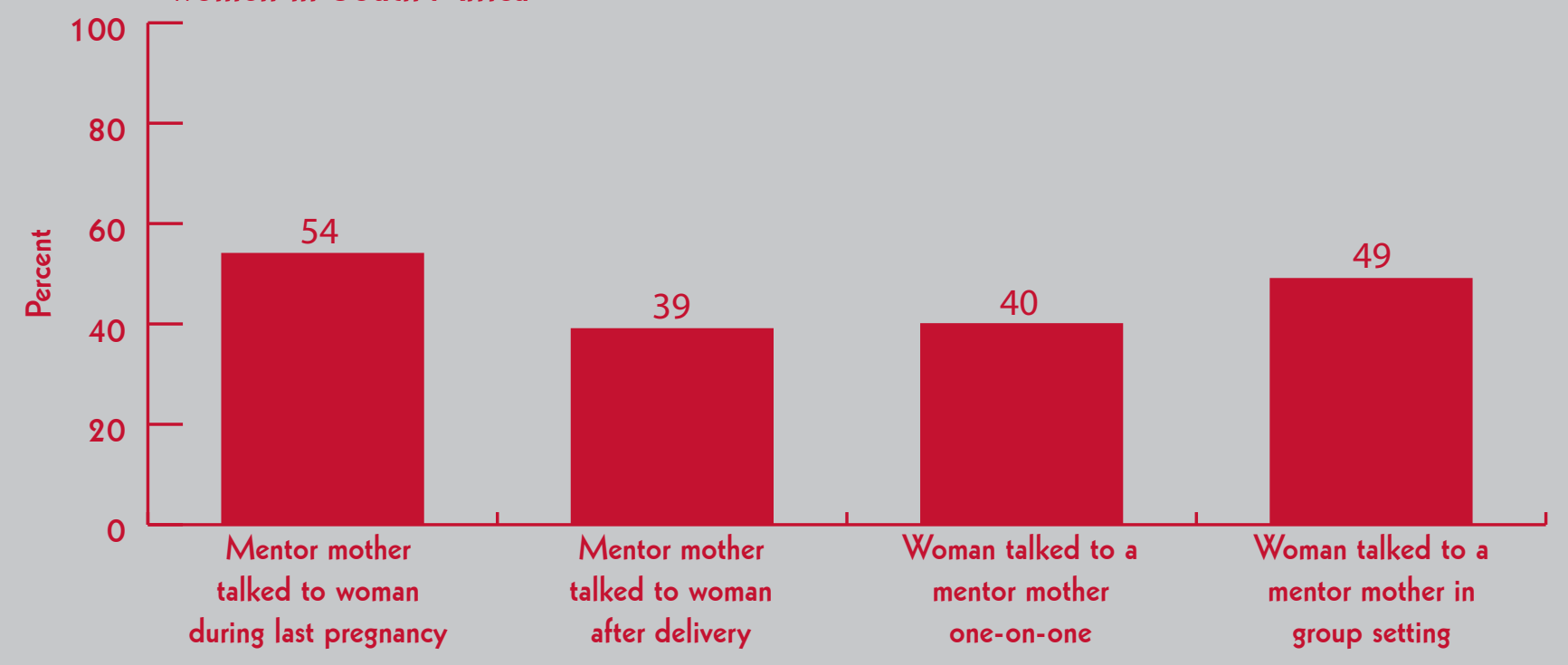

- reveal their HIV status to at least one person;

- receive CD4 testing during pregnancy;

- receive Nevirapine for themselves and their infants; and

- practice an exclusive method of infant feeding (in most cases, exclusive formula feeding).

Furthermore, they were less likely to report feeling alone in the world, overwhelmed by problems, and hopeless about the future [9]. The relevance of peer support approaches extends beyond the region. In India where peer psychosocial support was not offered at the study sites, HIV-positive women requested structured opportunities to meet and support one another [10].

\section{Staff training and use of peer educators im- proves infant feeding practices}

Up to 50 percent of infant infections occur because the parents use a non-exclusive feeding approach. Thus, support of appropriate

infant feeding practices is critical. But it can be challenging [11]. Recent research shows that exclusive breastfeeding is as likely to lead to HIV-free survival as exclusive formula feeding [12]. The recommendation in place at the time of the Horizons studies was for HIV-positive women to breastfeed exclusively unless the use of formula is determined to be "acceptable, feasible, affordable, safe, and sustainable” [13]. However, this recommendation was often difficult to put into practice in the field [14].

Horizons studies indicate that intensive interventions can positively affect infant feeding practice. A 2000-2002 study in Zambia identified factors that improve infant feeding knowledge and practice among HIV-positive mothers [15] (Figure 3). These include conscientious reinforcement of breastfeeding, community education and mobilization, and intensive training of clinic and community-based workers. In Swaziland, baseline data collection revealed incorrect information among providers, mothers, and families regarding appropriate feeding options for new mothers in the context of HIV. However, training of postnatal care providers produced significant improvements in infant feeding knowledge with associated increases 


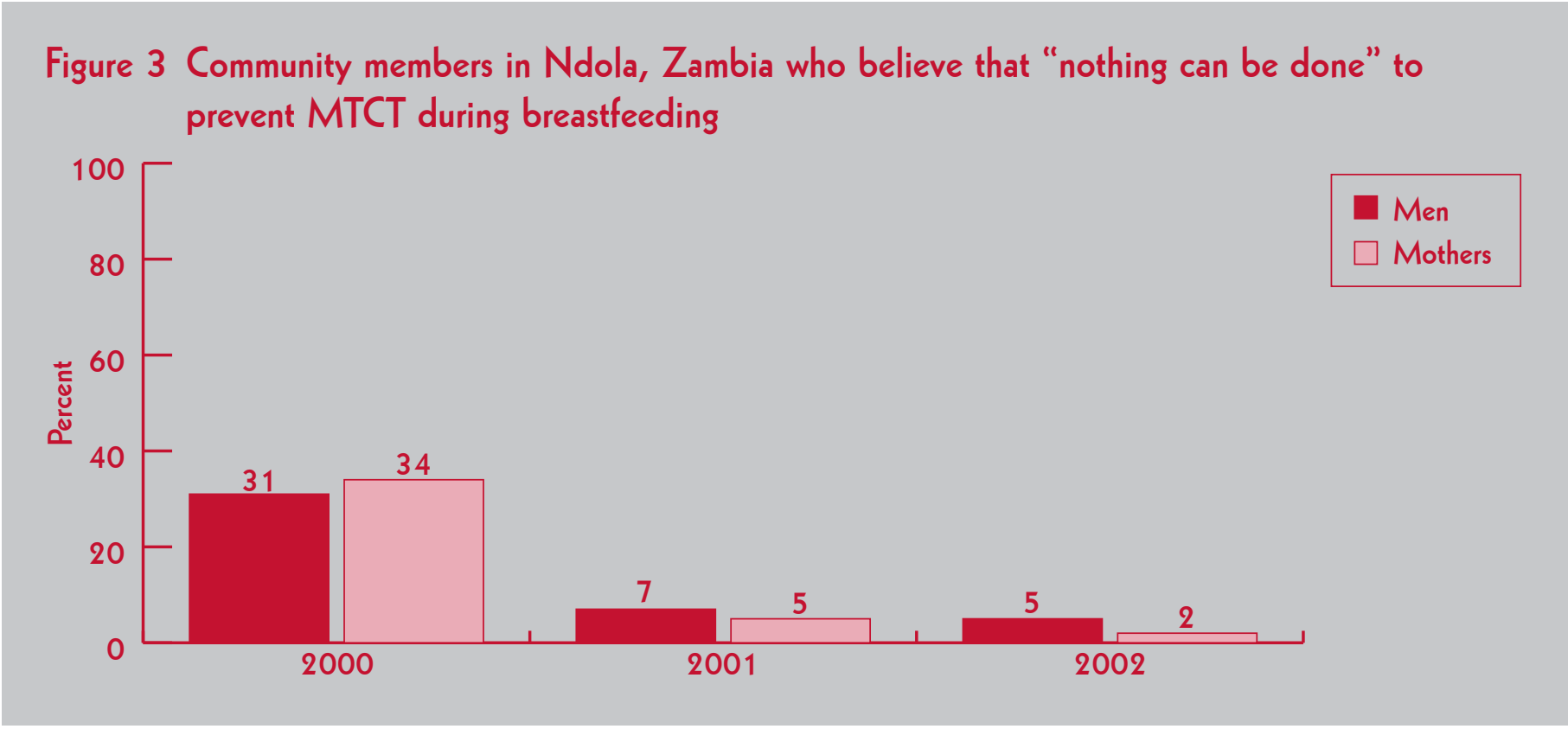

in proper breastfeeding practices among new mothers before hospital discharge [16]. The $\mathrm{m} 2 \mathrm{~m}$ evaluation in South Africa found that peer education and mentorship increased the likelihood of using an exclusive feeding method among women 4 to 12 weeks postpartum [9].

\section{Prioritizing comprehensive services is feasible}

A comprehensive approach to PMTCT should include linking HIV-positive women with family planning services to prevent unintended pregnancy [17]. A 2004 Horizons review of field experiences in ten countries in Africa, Asia, and Latin America found that PMTCT programs often miss opportunities to provide clients with family planning counseling. In Kenya and Zambia, for example, just half of HIV-positive women received information about family planning at an antenatal or postpartum visit [18] (Figure 4). Moreover, 2005 data from Kenya showed that most HIVpositive women did not plan to have additional children and intended to use family planning. But only half of new mothers reported discussing these issues with their provider [19]. In India, more than 80 percent of the postpartum women interviewed did not want more chil- dren, yet nearly half reported not using a family planning method, and only one-third reported receiving condoms from their PMTCT service provider following delivery [20].

Despite deficiencies in provision of family planning services to HIV-positive women, many of the necessary elements are in place. Family planning services are generally available at PMTCT sites. PMTCT provider training includes information about family planning. And programs generally incorporate both family planning and PMTCT promotional messages. The Horizons review highlighted ways to reach more women with family planning and PMTCT services by:

- integrating family planning into PMTCT services rather than offering them in parallel;

- building on positive attitudes toward condoms among HIV-positive women and men to promote dual protection;

- promoting values clarification with providers about reproductive rights; and

- reducing loss to follow up by strengthening linkages between ante- 
Figure 4 Percentage of antenatal and maternal-child health clients at PMTCT program sites who received antenatal postpartum family planning counseling in Lusaka, Zambia, 2000-02

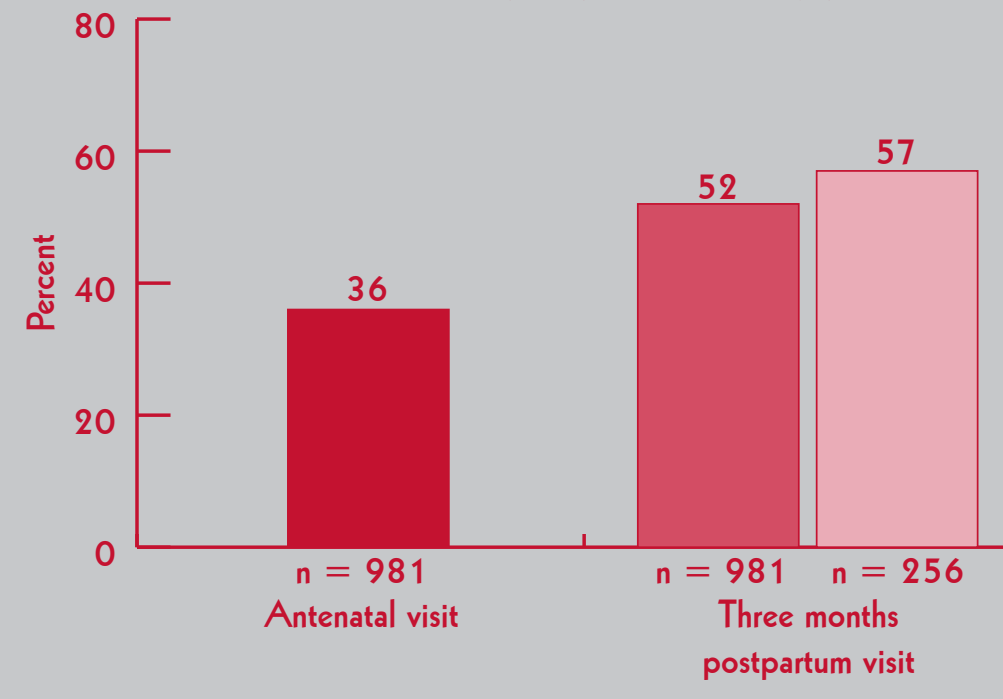

natal PMTCT and postpartum family planning services [18].

Horizons studies also identified needed improvements in links to care and treatment for HIV-positive women and their families, another cornerstone of comprehensive PMTCT programming [17]. In India, a diagnostic study examining the continuum of care for HIVpositive women found that 41 percent of those interviewed were aware of ART, but only one in five reported that their PMTCT provider informed them of this service. Among women on treatment, only 10 percent reported being referred to ART services by a PMTCT provider [10]. In a Horizons study in Botswana, a smaller proportion of pregnant women in comparison to postpartum women were on ART, suggesting the need for earlier ART eligibility and enrollment [21].

Keeping mothers and their infants linked to the health care delivery system after they give birth is an essential yet challenging component of comprehensive PMTCT programs. A Horizons intervention study in Swaziland demonstrated the benefits of adding a postpartum visit in the first week following delivery, a critical time in the care of new mothers and infants [22]. After the introduction of the intervention, postpartum women were three times more likely to access postnatal care within one week of delivery, and HIV-positive women and their infants were significantly more likely to have started cotrimoxazole, an important and simple therapy to decrease HIV-related illness (Table 1). Moreover, researchers saw improved communication between providers and clients, including provision of information to HIVpositive women on available services, such as family planning, food supplements, and support groups [16].

\section{Expanded coverage of HIV testing in antenatal care}

Many Horizons studies were conducted at a time when it became routine to offer HIV testing to all pregnant women [22-25]. Horizons studies documented that the vast majority of pregnant women who have had at least one antenatal care visit have undergone HIV testing. The proportion of postpartum women reporting receiving an HIV test at antenatal care sites in Kenya increased from 84 percent to 93 percent between 2004 and 2005 [26]. 
In Swaziland, this figure rose from 72 percent to 92 percent between 2006 and 2007 [16]. In India, nearly three-quarters of HIV positive women interviewed underwent HIV testing as part of their antenatal care [10]. These statistics offer strong evidence that HIV testing in antenatal care is becoming routine practice [27].

\section{High rates of disclosure by $H I V$-positive women}

With increased testing among pregnant women, it has become more common for those women to reveal their HIV status to another person. Horizons studies found that more than three-quarters of HIVpositive women surveyed in Botswana, India, Kenya, South Africa, and Swaziland [9, 10, 16, 21, 26], reported telling at least one person, most commonly a partner or husband, they were HIV-positive. This held constant despite wide differences in marriage rates in the study populations. Disclosure rates from these recent Horizons studies exceed those in a 2004 synthesis [28] Possible reasons for this increase include greater HIV awareness; maturation of PMTCT programs; a shift to routine availability of HIV testing for pregnant women; and improved and more accessible services for women newly diagnosed with HIV.

\section{Supporting proper use of antiretroviral prophylaxis}

Programs often report the number of HIV-positive pregnant women who start zidovudine (AZT) and receive nevirapine for PMTCT. However, the effectiveness of these programs is dependent on the proper use of these drugs.
Horizons examined the operational aspects that affect adherence to PMTCT drug regimens in Botswana and found that most HIV-positive pregnant women received only one post-test counseling session (Table 2), providing limited opportunity to explain and promote the proper use of antiretroviral prophylaxis. Half of the treatment-adherence counseling staff reported that they discussed the importance of taking the correct dose and taking it on schedule with their clients. But far fewer reported discussing other important topics, such as the purpose of medications and side effects. While the majority of women remembered information on why AZT is needed, how to take it, and the importance of taking it on schedule, only 14 percent recalled receiving written materials developed specifically for HIV-positive women [21].
Table 2 Number of post-HIV-test sessions with counselor at ANC clinic in Francistown, Botswana

\begin{tabular}{|c|c|c|}
\hline & $\begin{array}{c}\text { HIV-positive } \\
\text { pregnant women } \\
(n=109) \\
\text { Number (\%) }\end{array}$ & $\begin{array}{c}\text { HIV-positive } \\
\text { postnatal ward women } \\
(n=116) \\
\text { Number }(\%)\end{array}$ \\
\hline 1 & 74 (68\%) & 81 (70\%) \\
\hline 2 & 21 (19\%) & $16(14 \%)$ \\
\hline 3 or more & $14(13 \%)$ & $19(16 \%)$ \\
\hline
\end{tabular}


Horizons studies in Botswana, India, Kenya, and South Africa found that about eight out of ten women who were tested for HIV and received positive test results reported starting antiretroviral prophylaxis during their pregnancy. These self-reports are consistent with service statistics from 13 country programs supported by the Elizabeth Glaser Pediatric AIDS Foundation [29].

The Botswana study provided some insight into how often and why women missed doses among those who are taking a complex regime. The majority of HIV-positive pregnant and postpartum women reported that it was easy to take their AZT regimen properly. And nine out of ten had taken the appropriate number of tablets the two days prior to the interview.

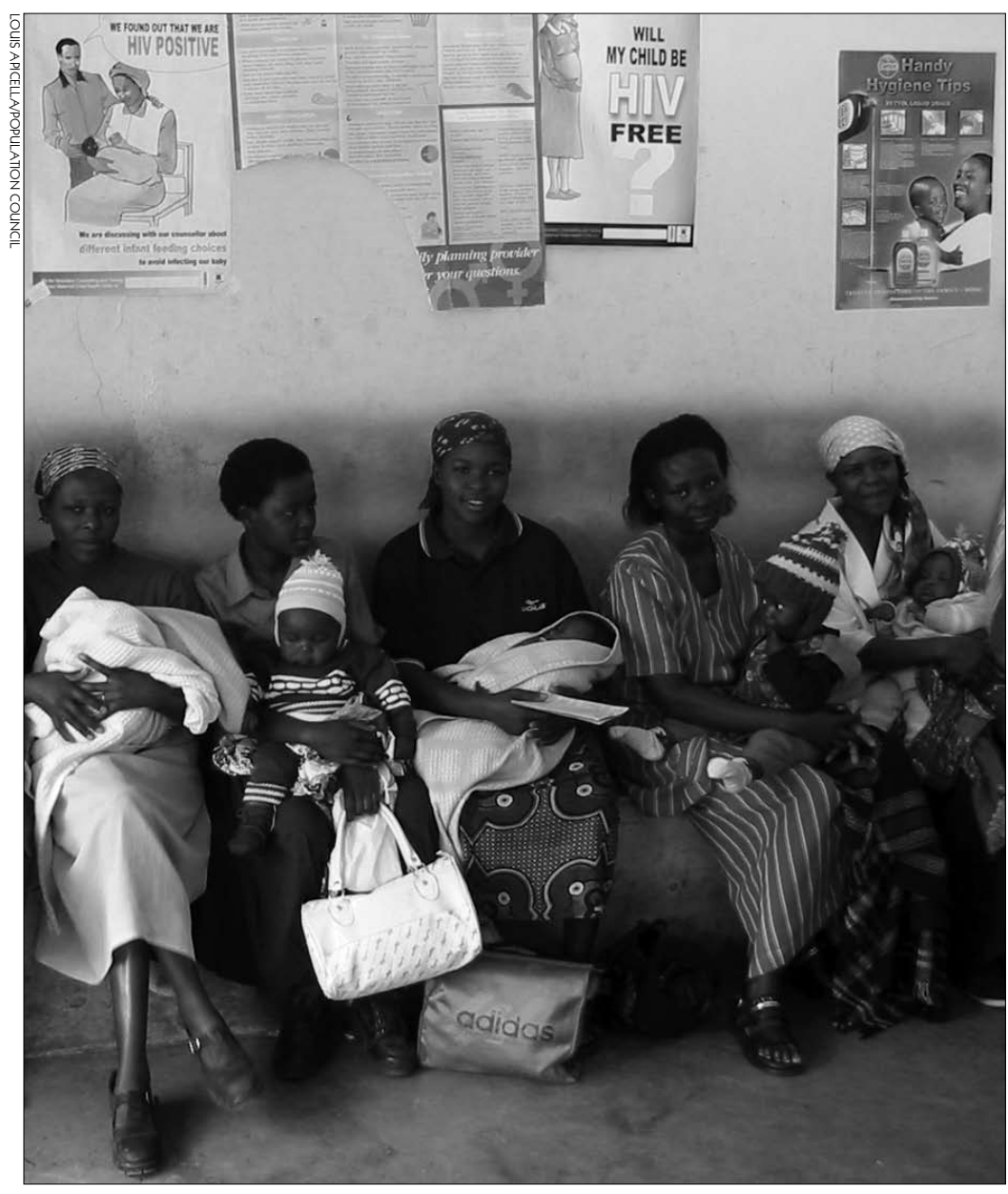

Horizons research studies have answered critical questions about how PMTCT programs function in the real world and how better to serve women and infants in many settings.
However, 30 to 40 percent reported missing at least some doses during their pregnancies. One of the main reasons for failing to take their medication was that they had run out.

The Botswana study suggests several relatively simple program actions for increasing proper use of PMTCT regimens. These include:

- standardizing the content of post-test counseling by using job aids;

- providing at least two post-test counseling sessions per woman;

- reducing the frequency of refills; and

- encouraging women to refill their supply before they run out of pills [21].

PMTCT services are enhanced when programs determine whether pregnant women are eligible for ART based on CD4 levels. Determining the CD4 levels of HIV-positive pregnant women enables women with advanced disease to receive treatment for their own health and to access a more effective regimen to reduce transmission to their babies [17]. Findings from Botswana, South Africa, and Swaziland [9, 16, 21] show that the majority of pregnant and recent postpartum HIV-positive women got CD4 testing. In South Africa and Swaziland [9, 16], the programs that were evaluated specifically promoted CD4 testing as part of comprehensive care for HIV-positive women.

\section{Use of Research Results}

The Horizons Program has emphasized the dissemination of data to increase the use of research results. The studies in Kenya and Zambia generated evidence that shaped the expansion of PMTCT services in both countries. For example, in Kenya, the study produced a training curriculum, educational materials, and an information system that were 
subsequently adopted by the National AIDS Control Program of Kenya for their nationwide PMTCT program. In South Africa, the Horizons evaluation of the mothers 2 mothers program was the first external evaluation of a well-known program, providing quantitative evidence of the benefits of peer psychosocial support. Based in part on the Horizons evaluation, the $\mathrm{m} 2 \mathrm{~m}$ program has been expanded in several sub-Saharan African countries.

\section{Conclusion and Future Priorities for Research and Programs}

Since the inception of PMTCT programming in resource-constrained settings, Horizons has undertaken operations research studies to answer critical questions about how programs function in the real world and how better to serve women and infants in need. The first set of studies documented the feasibility and challenges of PMTCT programs, while the second assessed different approaches to providing comprehensive services. While this overall research portfolio yielded a number of insights, a few deserve to be highlighted.

While the ease of the antiretroviral prophylaxis regimen is important, the more complex yet most effective regimen is both feasible and acceptable, as demonstrated in Botswana. In addition, this study identified the importance of sufficient counseling to maximize adherence to the regimen and to maintain ongoing contact with clients to monitor side effects or other problems.

Challenges to infant feeding can only be overcome through structured support for women both while pregnant and after childbirth. Successful approaches documented by Horizons include peer support, making adjustments to postnatal care, and making counseling about infant feeding an integral part of HIV services in the antenatal care setting in South Africa, Swaziland, and Zambia.

Finally, our findings underscore the need to establish close ties with other services in order to provide a continuum of care from antenatal to postnatal PMTCT services and onto HIV care. Horizons studies in Botswana, India, South Africa, and Zambia suggest that:

- PMTCT programs should strengthen their referral links between antenatal care, delivery, child health, and HIV services;

- better equip PMTCT providers to inform and counsel women about a continuum of care; and

- engage community groups and NGOs to maintain contact with women and link them and their families to care.

A critical next step is to test programmatic strategies for supporting and tracking women and infants beyond the early postpartum period. This would create a seamless continuum from PMTCT programs to the early identification of HIV-infected infants to provision of HIV care for the mother and infant as needed. Adequate follow up would encourage safer forms of feeding, link women to family planning services, and test infants at multiple points in their lives. Such follow up is particularly necessary for continued testing of infants to measure program effect. Until now, determining actual transmission rates has been rare, and programs have relied on proxy measures of effectiveness. The testing of HIV-exposed infants repeatedly, such as at six weeks postpartum, six weeks post weaning, and 18 months would allow the estimation of early infection and late infection as well as HIV-free survival. Such research could also answer operational questions regarding how to provide infant testing as a routine service, and how to link HIV-positive infants with care. 
Primary prevention of HIV among women of reproductive age is an important approach to PMTCT. Operations research can test new counseling protocols for use in antenatal care that reinforce and encourage HIV prevention among women who test HIV-negative as well as "prevention among positives" counseling for those testing positive. This is particularly pertinent because some research suggests that women are at increased vulnerability to HIV during pregnancy [30].

Finally there is an urgent need to expand the geographic coverage of PMTCT services.
While uptake of HIV testing and antiretroviral prophylaxis are high in a limited number of settings, as indicated by Horizons studies, there is a great need to expand services at the national level. Data from Horizons studies have demonstrated what is working well and what can be improved at the site level. We hope that policy makers and program managers use these data as they commit to making high-quality, comprehensive PMTCT services available in harder to reach areas and populations. 


\section{APPENDIX}

\section{Sample characteristics and study design among Horizons PMTCT studies, 1999-2007}

\begin{tabular}{|c|c|c|c|}
\hline Study title and country & Year & Study design & Sample size \\
\hline $\begin{array}{l}\text { Kenya: Testing the feasibility and impact of } \\
\text { a package of services for reducing mother to } \\
\text { child transmission of HIV [19] }\end{array}$ & $\begin{array}{l}1999- \\
2003\end{array}$ & $\begin{array}{l}\text { Cohort study; purposive sample of } \\
\text { health facilities }\end{array}$ & 1,300 women \\
\hline $\begin{array}{l}\text { Zambia: Testing the feasibility and impact of } \\
\text { a package of services for reducing mother to } \\
\text { child transmission of HIV }\end{array}$ & $\begin{array}{l}1999- \\
2003\end{array}$ & $\begin{array}{l}\text { Cohort study; purposive sample of } \\
\text { health facilities }\end{array}$ & 1,002 women \\
\hline $\begin{array}{l}\text { Zambia: Empowering communities to respond } \\
\text { to HIV/AIDS Ndola demonstration project } \\
\text { on maternal and child health [15] }\end{array}$ & $\begin{array}{c}2000- \\
2002\end{array}$ & $\begin{array}{l}\text { Pre-post intervention; cross sectional } \\
\text { surveys, observations }\end{array}$ & $\begin{array}{l}1,274 \text { women in health facilities; } \\
2818 \text { men and women in communities; } \\
206 \text { providers; } 1,278 \text { observations }\end{array}$ \\
\hline Multi-country UN Evaluation [5] & 2003 & $\begin{array}{l}\text { Descriptive evaluation; interviews } \\
\text { with stakeholders; review of program } \\
\text { reports }\end{array}$ & $\begin{array}{l}11 \text { countries in Africa, Asia, and Latin } \\
\text { America }\end{array}$ \\
\hline $\begin{array}{l}\text { Multi-country Review of Field Experiences: } \\
\text { Integration of Family Planning and PMTCT } \\
\text { Services }\end{array}$ & 2004 & Review; interviews with stakeholders & $\begin{array}{l}10 \text { countries in Africa, Asia, and Latin } \\
\text { America }\end{array}$ \\
\hline $\begin{array}{l}\text { Kenya: Community-based Approaches to } \\
\text { Prevention of Mother-To-Child Transmission } \\
\text { of HIV: Findings from a Low-Income } \\
\text { Community in Kenya }\end{array}$ & $\begin{array}{l}2004- \\
2005\end{array}$ & $\begin{array}{l}\text { Pre-post intervention; cross sectional } \\
\text { surveys, purposive sample of health } \\
\text { facilities }\end{array}$ & $\begin{array}{l}3,616 \text { surveys and } 58 \text { in-depth } \\
\text { interviews of HIV-negative and HIV- } \\
\text { positive women }\end{array}$ \\
\hline $\begin{array}{l}\text { Botswana: Evaluation of HIV Counseling and } \\
\text { Testing in ANC Settings and Adherence to } \\
\text { Short Course Antiretroviral Prophylaxis for } \\
\text { PMTCT in Francistown, Botswana [21] }\end{array}$ & 2005 & $\begin{array}{l}\text { Descriptive evaluation; cross sectional } \\
\text { surveys, observations, review of } \\
\text { records, purposive sample of health } \\
\text { facilities }\end{array}$ & $\begin{array}{l}247 \text { interviews of HIV-positive } \\
\text { pregnant and postpartum women; } \\
43 \text { interviews of providers; } 22 \\
\text { observations }\end{array}$ \\
\hline $\begin{array}{l}\text { India: Continuum of Care for HIV-Positive } \\
\text { Women Accessing Programs to Prevent Parent } \\
\text { to Child Transmission: Findings from India } \\
\text { [10] }\end{array}$ & 2005 & $\begin{array}{l}\text { Diagnostic study; cross sectional } \\
\text { surveys, purposive sample of health } \\
\text { facilities }\end{array}$ & $\begin{array}{l}268 \text { surveys and } 47 \text { in-depth } \\
\text { interviews of HIV-positive pregnant and } \\
\text { postpartum women; } 32 \text { interviews of } \\
\text { providers }\end{array}$ \\
\hline $\begin{array}{l}\text { South Africa: Evaluation of the } \\
\text { mothers } 2 \text { mothers program in KwaZulu-Natal, } \\
\text { South Africa [9] }\end{array}$ & $\begin{array}{c}2005- \\
2006\end{array}$ & $\begin{array}{l}\text { Pre-post intervention; cross sectional } \\
\text { surveys, in-depth interviews } \\
\text { purposive sample of health facilities }\end{array}$ & $\begin{array}{l}\text { 1,056 surveys of HIV-positive } \\
\text { women; } 18 \text { in-depth interviews }\end{array}$ \\
\hline $\begin{array}{l}\text { Swaziland: Repositioning Postnatal Care in a } \\
\text { High HIV Environment: Swaziland [16] }\end{array}$ & $\begin{array}{l}2006- \\
2007\end{array}$ & $\begin{array}{l}\text { Pre-post intervention; cross sectional } \\
\text { surveys, observations, review of } \\
\text { records, purposive sample of health } \\
\text { facilities }\end{array}$ & $\begin{array}{l}794 \text { surveys of HIV-negative and } \\
\text { HIV-positive women; } 89 \text { surveys of } \\
\text { providers; } 376 \text { observations; } 227 \\
\text { review of records }\end{array}$ \\
\hline
\end{tabular}


1. UNAIDS, "Report on the global AIDS epidemic; A UNAIDS $10^{\text {th }}$ anniversary special edition" (Geneva: UNAIDS, 2006).

2. M. G. Fowler et al., "Reducing the risk of mother-to-child human immunodeficiency virus transmission: past successes, current progress and challenges, and future directions," American Journal of Obstetrics \& Gynecology 197 (3 suppl): S3-S9 (2007).

3. N. Shaffer et al., "Short-course zidovudine for perinatal HIV-1 transmission in Bangkok, Thailand: A randomized controlled trial," Lancet 353 (9155): 773-780 (1999).

4. L. A. Guay et al., "Intrapartum and neonatal single-dose nevirapine compared with zidovudine for prevention of mother-to-child transmission of HIV-1 in Kampala, Uganda: HIVNET 012 randomized trial," Lancet 354 (9181): 795-802 (1999).

5. N. Rutenberg et al., "Evaluation of United Nations-supported pilot projects for the prevention of mother-to-child transmission of HIV" (New York: UNICEF and Population Council, 2003).

6. C. Kankas, "Provision of VCT and ARVs: achievements and challenges" (paper presented at Horizons PMTCT Symposium, Washington, DC, December 2003).

7. R. Nduati, "Infant feeding counseling within PMTCT services: How well does it promote good feeding practices?" (paper presented at Horizons PMTCT Symposium, Washington, DC, December 2003).

8. World Health Organization, "New data on the prevention of mother-to-child transmission of $\mathrm{HIV}$ and their policy implications: Conclusions and recommendations, WHO technical consultation on behalf of the UNFPA/UNICEF/WHO/ UNAIDS Inter-agency Task Team on motherto-child transmission of HIV" (Geneva: World Health Organization, 2001).

9. C. Baek et al., "Key findings from an evaluation of the mothers2mothers program in KwaZuluNatal, South Africa," Horizons Final Report (Washington, DC: Population Council, 2007).
10. V. S. Mahendra et al., "Continuum of care for HIV-positive women accessing programs to prevent parent-to-child transmission: Findings from India," Horizons Final Report (Washington, DC: Population Council, 2007).

11. M. G. Fowler, M. L. Newell, "Breastfeeding and HIV-1 transmission in resource limited settings," Journal of Acquired Immune Deficiency Syndrome 30 (2): 230-9 (2002).

12. World Health Organization, "HIV and infant feeding: new evidence and programmatic experience: Report of a technical consultation held on behalf of the Inter-agency Task Team (IATT) on prevention of HIV infections in pregnant women, mothers and their infants, Geneva, Switzerland, 25-27 October 2006" (Geneva: World Health Organization, 2007).

13. World Health Organization, "Planning guide for national implementation of the global strategy for infant and young child feeding" (Geneva: World Health Organization, 2006).

14. T. Doherty et al., "Effectiveness of the WHO/ UNICEF guidelines on infant feeding for HIVpositive women: results from a prospective cohort study in South Africa," AIDS 21 (13): 1791-1797 (2007).

15. Hope Humana et al., "Empowering communities to respond to HIV/AIDS-Ndola demonstration project on maternal and child health: Operations research final report," Horizons Final Report (Washington, DC: Population Council, 2003).

16. C. Warren et al., "Repositioning postnatal care in a high HIV environment: Swaziland," Horizons Final Report (Washington, DC: Population Council, 2008).

17. Inter-agency Task Team on Prevention of HIV Infection in Pregnant Women, Mothers and their Children, "Guidance on global scale-up of the prevention of mother-to-child transmission of HIV: Towards universal access for women, infants and young children and eliminating HIV and AIDS among children" (Geneva: World Health Organization, 2007). 
18. N. Rutenberg, C. Baek, "Field experiences integrating family planning into programs to prevent mother-to-child transmission of HIV," Studies in Family Planning 36 (3): 235-245 (2005).

19. C. Baek et al., "Assessing HIV-positive women's fertility desires and demand for family planning in PMTCT programs in Nairobi, Kenya" (paper presented at $133^{\text {rd }}$ Annual Meeting of the American Public Health Association, Philadelphia, 10-14 December 2005).

20. V. S. Mahendra et al., "Fertility intentions and family planning needs of HIV-infected women receiving PPTCT services in India-Experiences from diagnostic research" (paper presented at Scaling-up FP/MNCH Best Practices: Achieving MDGs in ANE, Bangkok, Thailand, 7 September 2007).

21. C. Baek et al., "Evaluation of HIV counseling and testing in ANC settings and adherence to short course antiretroviral prophylaxis for PMTCT in Francistown, Botswana," Horizons Final Report. Washington, DC: Population Council, 2009).

22. O. Bolu et al., "Approaches for scaling up human immunodeficiency virus testing and counseling in prevention of mother-to-child human immunodeficiency virus transmission settings in resourcelimited countries," American Journal of Obstetrics \& Gynecology 197 (3 suppl): S17-S25 (2007).

23. UNAIDS and World Health Organization, "UNAIDS/WHO policy statement on HIV testing" (Geneva: UNAIDS and World Health Organization, 2004).

24. World Health Organization, "The right to know: New approaches to HIV testing and counselling" (Geneva: World Health Organization, 2004).

25. World Health Organization, "Towards universal access: scaling up priority HIV/AIDS interventions in the health sector: Progress report" (Geneva: World Health Organization, 2007).

26. S. Kaai et al., "Community-based approaches to prevention of mother-to-child transmission of HIV: Findings from a low-income community in Kenya," Horizons Final Report (Washington, DC: Population Council, 2007).

27. USAID et al., "Coverage of selected services for HIV/AIDS prevention, care and support in low and middle income countries in 2003" (Washington, DC: The Policy Project, 2004).

28. A. Medley et al., "Rates, barriers and outcomes of HIV serostatus disclosure among women in developing countries: Implications for prevention of mother-to-child transmission programs," Bulletin of the World Health Organization 82 (4): 299-307 (2004).
29. T. Sripipatana et al., "Site-specific interventions to improve prevention of mother-to-child transmission of human immunodeficiency virus programs in less developed settings," American Journal of Obstetrics \& Gynecology 197 (3 suppl): S83-S89 (2007).

30. R. H. Gray et al., "Increased risk of incident HIV during pregnancy in Rakai, Uganda: A prospective study," Lancet 366 (9492): 1182-1188 (2005).

31. N. Druce, A. Nolan, "Seizing the big missed opportunity: Linking HIV and maternity care services in sub-Saharan Africa," Reproductive Health Matters 15 (30): 190-201 (2007).

31. UNICEF. "PMTCT report card 2005: Monitoring progress on the implementation of programs to prevent mother to child transmission of HIV," UNICEF/Ngashi (2005). 


\section{ACKNOWLEDGMENTS}

The authors would like to extend their appreciation to the co-principal investigators and other individuals who contributed to the studies presented in this paper. These studies were only made possible through much collaboration and enormous effort from numerous individuals. The authors extend specific thanks to Charlotte Warren, Vaishali Mahendra, and Ellen Weiss from the Horizons Program for their contributions to these studies and review of this paper. Thanks are extended to Scott Kellerman for his expert review of this paper. Thanks to Gina Duclayan and Hena Khan for editing and Sherry Hutchinson for layout. Funding for these studies was made available by the United States Agency for International Development, UN, and WHO. Finally, the authors express deep appreciation to the thousands of women in resource-constrained settings who agreed to participate in these studies. 
Authors: Carolyn Baek, Population Council, New York, USA and Naomi Rutenberg, Population Council, Washington, DC, USA
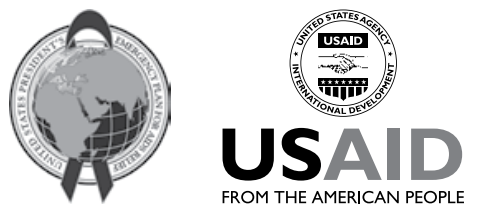

This study and final report were made possible by the President's Emergency Plan for AIDS Relief and the generous support of the American people through the United States Agency for International Development (USAID) under the terms of Cooperative Agreement No. HRNA-00-97-00012-00. The contents are the responsibility of the Horizons

Published in April 2010.

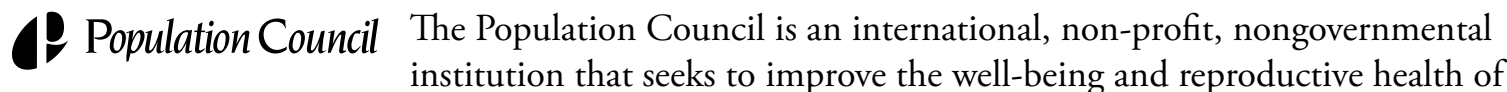
current and future generations around the world and to help achieve a humane, equitable, and sustainable balance between people and resources. The Council conducts biomedical, social science, and public health research and helps build research capacities in developing countries. Established in 1952, the Council is governed by an international board of trustees. Its New York headquarters supports a global network of regional and country offices.

Copyright (C) 2010. The Population Council Inc.

Suggested citation: Baek, Carolyn and Naomi Rutenberg. 2010. "Looking backward, moving forward: Implementing PMTCT programs in resource-constrained settings, Horizons studies 1999-2007," Horizons Synthesis Background Papers. Washington, DC: Population Council.

This document may be reproduced in whole or in part without permission of the Population Council provided full source citation is given and the reproduction is not for commercial purposes. 


USAID

Population Council

HIV and AIDS Program

4301 Connecticut Ave NW, Suite 280

Washington, DC 20008

Tel: 202-237-9400

Fax: 202-237-8410

pubinfo@popcouncil.org 